\title{
Las pilas bautismales en la Diócesis de Córdoba. El caso singular de Los Pedroches
}

\author{
Ana M. ${ }^{a}$ Acedo Gómez \\ Universidad de Córdoba \\ anaacedo@gmail.com
}

La extensión territorial que ocupa la actual Diócesis de Córdoba se encontró durante cinco siglos bajo el dominio musulmán, tiempo en el que sus edificaciones destinadas al culto cristiano fueron escasas en número, y pobres en su arquitectura y ornamentación. No fue hasta después de la reconquista de la capital cordobesa en 1236, cuando se procedió a restaurar su territorio, configurándose progresivamente conforme aumentaban las villas recuperadas de norte a sur, correspondiéndole prácticamente la extensión del antiguo reino almohade.

Junto con la restauración del territorio diocesano, se fundan en el siglo XIII 107 parroquias matrices (Nieto, 2003: 77), número que irá variando con la despoblación de algunos de sus asentamientos y la aparición de otros nuevos. La arquitectura de sus templos, en la capital, la llevaron a cabo maestros de obra procedentes posiblemente del norte peninsular, que desarrollaron un trabajo ecléctico, incorporando a sus conocimientos, ya desfasados, lo local imperante, y las nuevas tendencias establecidas en los años que duraron las construcciones. Se correspondió pues con un románico muy tardío, contaminado por un gótico incipiente mezclado con elementos mudéjares. Si bien dichos templos tuvieron buena pervivencia, en gran parte del resto de villas que conformaban la Diócesis fueron sustituidos en los siglos posteriores, muchas veces por la necesidad de ampliar la planta de los mismos, y en otras ocasiones para cambiar su estructura pobre, de madera, por otra de sillares.

Aunque se conservan en la Diócesis varias piscinas de inmersión paleocristianas, no cuentan con ninguna de las pilas bautismales primigenias de sus parroquias matrices, debiéndonos remontar a las últimas décadas del siglo XV para encontrar las más antiguas y primando las de siglos posteriores, entre las que abundan aquellas de estética barroca. Posiblemente el motivo sea el empleo en su construcción de algún tipo de material perecedero o considerado «impuros», tal como el barro, que propiciara su eliminación.

Artísticamente, suelen ser de mayor calidad tanto técnica como material, las pertenecientes a las parroquias de las villas que se encontraban bajo el dominio durante el Antiguo Régimen, de señoríos nobiliarios o de órdenes religiosas. Este hecho se debe a que muchas de ellas fueron costeadas directamente por nobles o clérigos acaudalados que trataron de dejar impronta a través de la donación de elementos artísticos, especialmente religiosos, usualmente como medio propagandístico. Gran número de estas pilas incluyen un sello identitario, en forma de escudo o símbolo a través del cual poder relacionarlas con su donante.

Dejando a un lado estos blasones, pocos son los detalles dignos de apreciación con que nos obsequiaron sus canteros, pues carecen en su mayoría de otras singularidades de tipo iconográfico en su labra, y se limitan al uso de gallones y molduras más o menos laboriosas como ornamento. A pesar de estas carencias, sí que constituyen un amplio catálogo en cuanto a su variedad material y morfológica, apareciendo grupos diferenciados según su datación y ubicación geográfica dentro de la provincia.

La piedra con que están elaboradas es de índole diversa, recurriendo casi siempre al material existente en canteras activas a nivel local o en villas próximas. Generalmente se extrae en la misma provincia de Córdoba, aunque hay evidencias escritas que testimonian la saca de piedra de canteras como la de Pedrera ${ }^{1}$, Sevilla, para emplearla en la capital cordobesa, de la que dista más de setenta kilómetros.

Se puede generalizar al comentar las pilas pertenecientes a las actuales vicarías de la ciudad, Valle del Guadalquivir y la campiña, pues bebieron de un mismo estilo, el dominante en el resto de Andalucía. En este caso, abundan las calizas blancas y areniscas para las fuentes ejecutadas 
TORRECAMPO
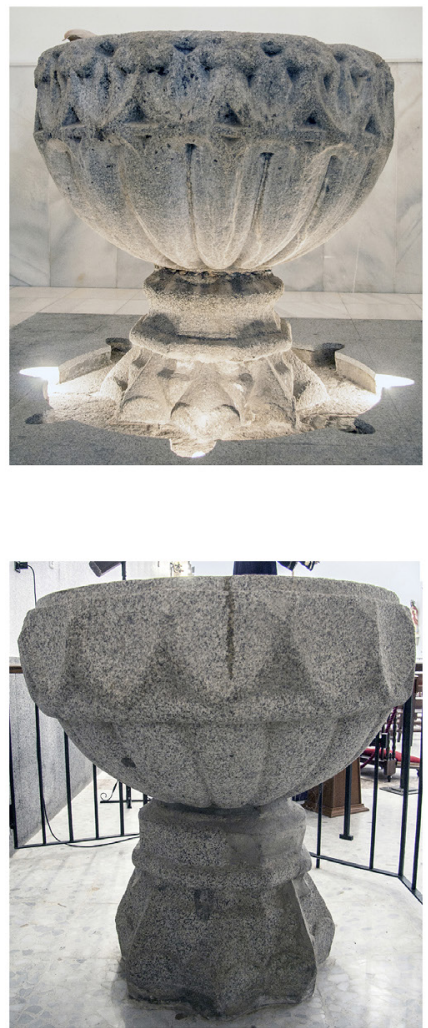

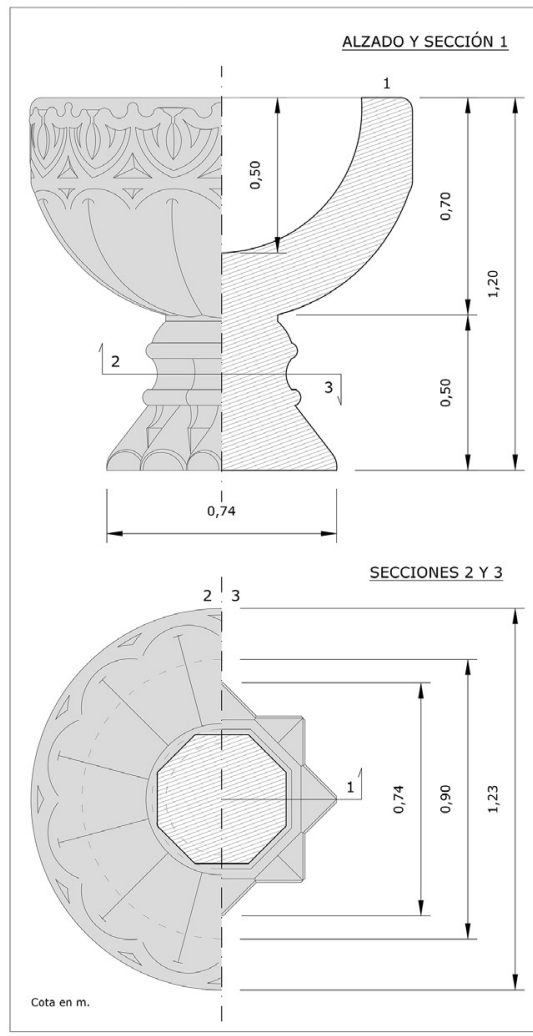

\section{ALCARACEJOS}

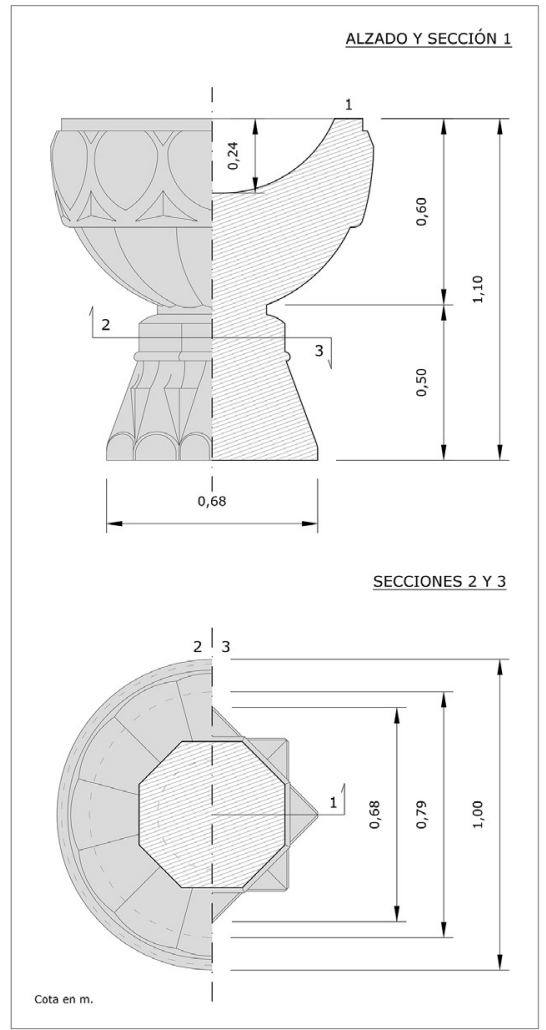

1. Pilas bautismales de la parroquia de San Sebastián, Torrecampo (última década siglo XV); y de la parroquia de San Andrés, Alcaracejos (alrededor de 1500)

hasta las primeras décadas del siglo XVI. Posteriormente, el empleo habitual es el de mármoles blancos, durante el siglo XVI e inicios del siglo XVII, y seguidamente pseudo mármoles rojos y negros, normalmente jaspeados, de las canteras de Cabra, Priego, Carcabuey, y de otras próximas a la capital (como la existente en la betada de la Casilla de los Ciegos, de la que se extraía el llamado mármol cárdeno de Córdoba). Dentro del abanico de materiales con que se ejecutaron encontramos un par de casos singulares, que se dan con el empleo de la piedra molinaza o arenisca roja de Montoro, usada para la pila de Adamuz, y el alabastro ónice amarillo, quizás de Cabra², en el caso de la pila de Zuheros. También existen ejemplos en que, dado el elevado coste de la piedra noble, se optó por ejecutar la pieza en caliza y simular posteriormente su apariencia marmórea con la aplicación de un revestimiento de estuco, tal como ocurre con las pilas bautismales de La Carlota o de la ruteña aldea de Zambra.
Cuenta la diócesis además con pilas elaboradas en barro vidriado, de estética mudéjar y propias del tránsito entre los siglos XV y XVI. Pertenecen a una tipología de la que existen ejemplares similares en Sevilla, Jaén y Málaga, así como en poblaciones de las Islas Canarias y Sudamérica, hacia donde se exportaron con afán evangelizador. Desgraciadamente su número que fue mayor, se redujo al ser sustituidas por otras realizadas en piedra, debido a la existencia de disposiciones eclesiásticas que mandaron su eliminación, como se refleja en los preceptos dados en las visitas generales a las parroquias en que existían. De las cinco que llegaron intactas al siglo XX (localizadas en pequeños núcleos que debieron escapar de las órdenes impuestas), se destruyeron tres durante los años de la Guerra Civil, quedando hoy día solo dos representaciones de las mismas, en las parroquias de Trassierra e Iznájar³.

En cuanto a las pilas bautismales pertenecientes a la actual Vicaría de la Sierra están casi en su totalidad ejecuta- 


\section{TORREFRANCA}
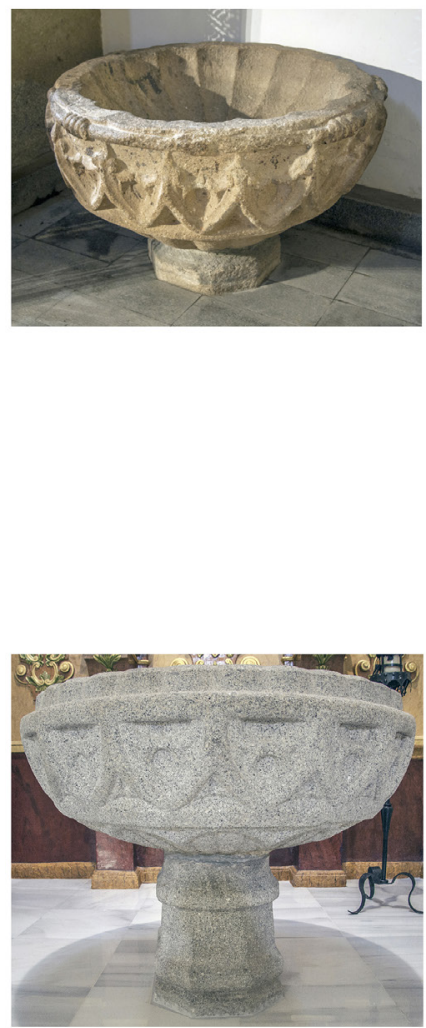

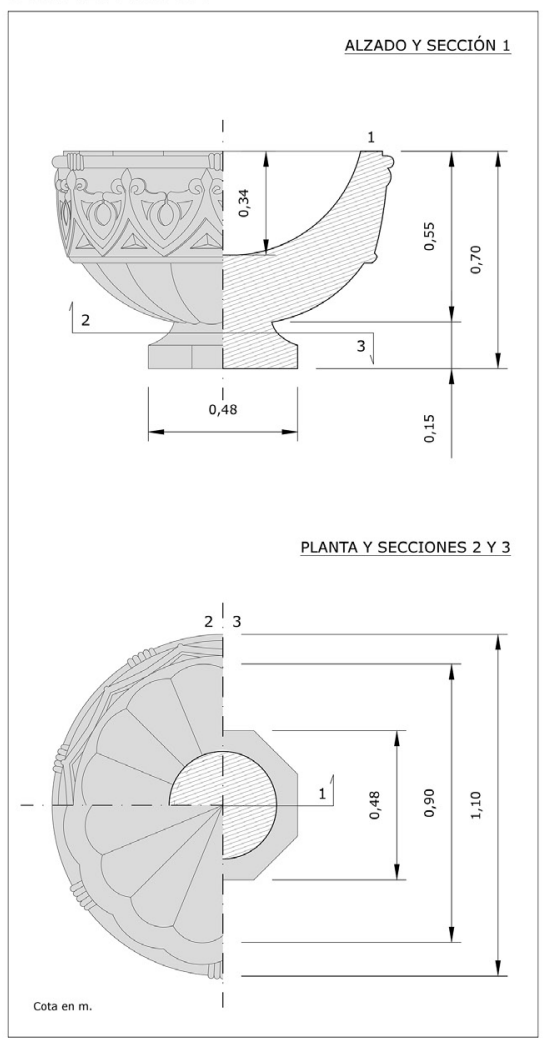

SANTA EUFEMIA

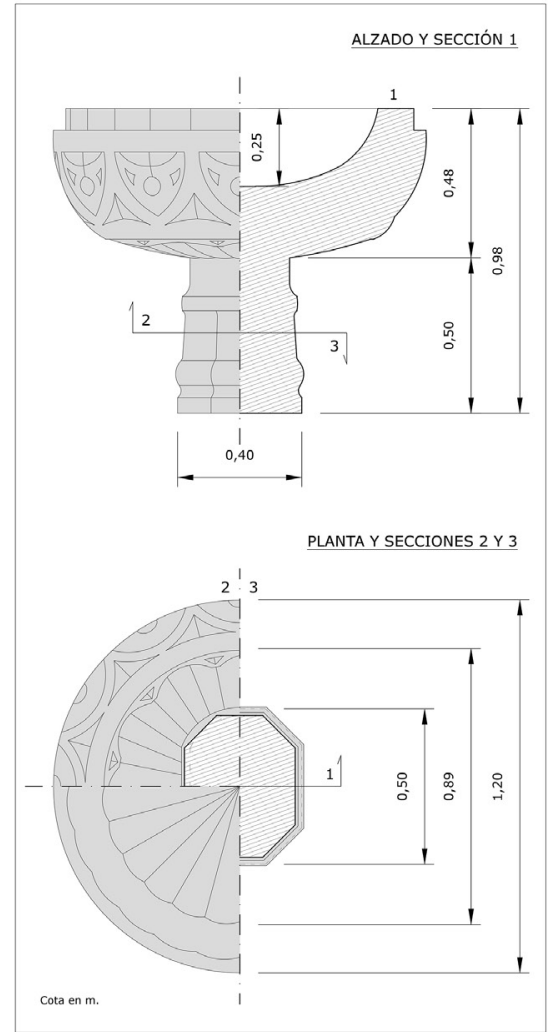

2. Pilas bautismales de la antigua parroquia de Santiago, Torrefranca, hoy Dos Torres (última década siglo XV); y de Ntra. Sra. de la Encarnación, Santa Eufemia (primera década siglo XVI)

das en piedra de granito, muy usada durante siglos en Los Pedroches, tanto en la arquitectura popular, como en la civil y religiosa. El motivo es la existencia de canteras históricas de este material en la zona, al estar atravesada por el batolito granodiorítico que discurre entre las provincias de Badajoz y Jaén, que da lugar a extensos afloramientos repartidos por toda la comarca. La empleada es una roca de grano medio, normalmente gris, aunque a veces también de mineral rosáceo, que presenta una tonalidad más o menos regular en todo el bloque según la calidad del mismo ${ }^{4}$.

\section{El caso de las pilas bautismales de Los Pedroches}

Existe en la comarca de Los Pedroches una tipología de pila bautismal originaria entre la última década del siglo XV y las primeras del siglo XVI, que nos permite realizar un análisis comparativo y evolutivo de un modelo propio y característico de esta zona, lindante con las provincias de Badajoz y Ciudad Real. Se trata de piezas elaboradas en granito local, del tipo de inmersión vertical y horizontal, y que presentan una cenefa a modo decorativo labrada en la banda superior de su copa. Son las pilas existentes en las parroquias matrices de las poblaciones de Santa Eufemia, Dos Torres (conformada por las antiguas Torremilano y Torrefranca), Alcaracejos, Añora, Torrecampo y Villanueva del Duque. A pesar de la falta de documentación escrita con que poder fecharlas, podrían estimarse como contemporáneas a la fábrica de los templos a los que pertenecen, exceptuando la de Santa Eufemia, obra posterior a un templo cuya obra se ha encuadrado en la transición de los siglos XIII-XIV.

La semejanza entre las pilas y su proximidad nos indica que posiblemente surgieron de un mismo taller de cantería que trabajó evolucionando un modelo único ${ }^{5}$, a la par que 


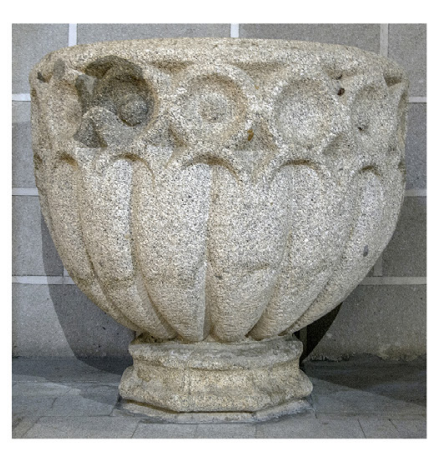

TORREMILANO
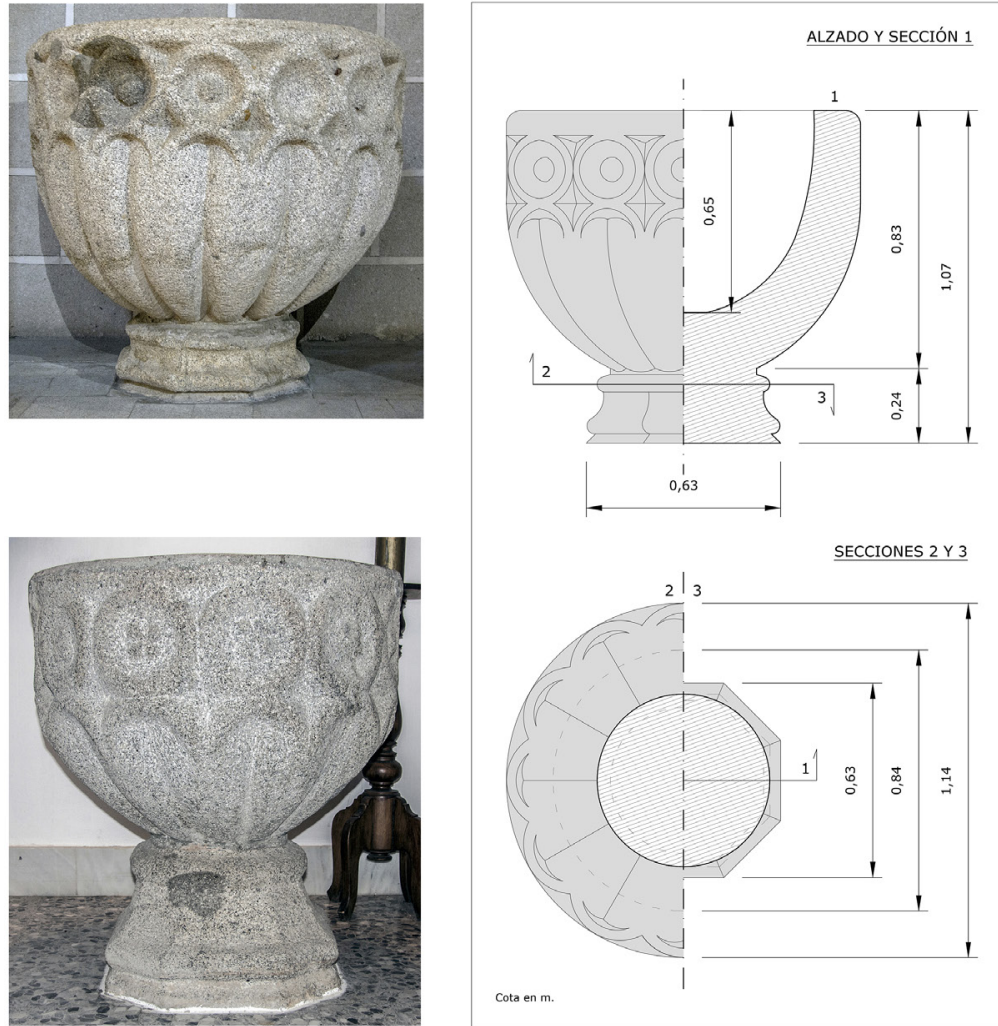

VILLANUEVA DEL DUQUE

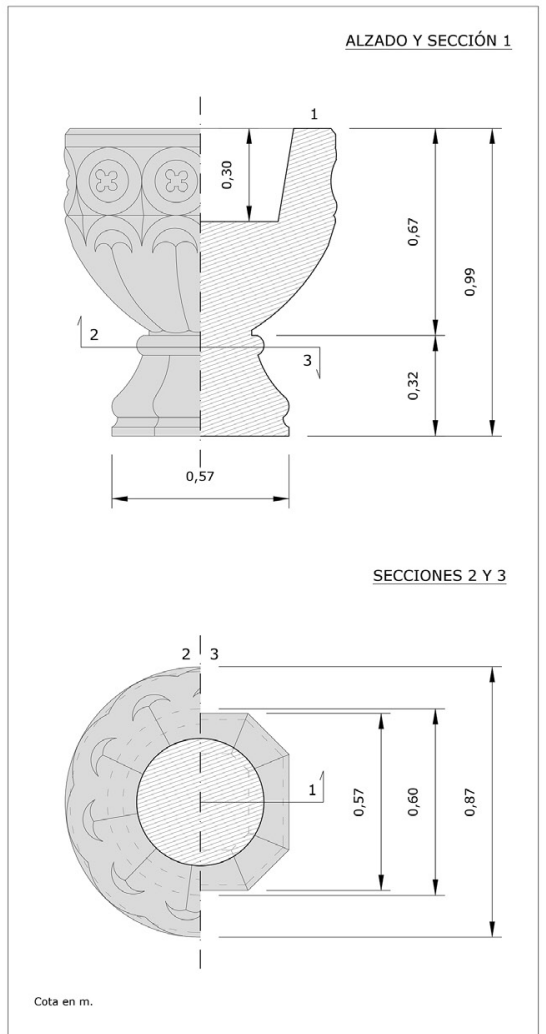

3. Pilas bautismales de la parroquia de Ntra. Sra. de la Asunción, Torremilano, hoy Dos Torres (última década siglo XV); y de la parroquia de San Mateo Apóstol, Villanueva del Duque (primera década siglo XVI)

lo adaptaba al estatus que por entonces tenía cada una de las villas en las que servirían.

Probablemente sea la de Torrecampo, junto con la de Torremilano, la más antigua de esta serie de pilas. De gran porte y labrada en granito, está conformada por una copa profunda de gran espesor, y un singular pie estrellado de ocho puntas en el apoyo, con sección octogonal en su mitad superior. La copa la constituye un casquete de esfera sobre el que apoya una banda cilíndrica decorada, esquema que se repetirá de manera similar en todas las pilas a estudio. Presenta en el casquete amplios gallones intercalados entre una liviana arquería [1].

De lo poco que sobrevivió de la antigua parroquia de Alcaracejos tras la Guerra Civil, es su pila bautismal. Se trata de un modelo simplificado y a menor escala de la pila de Torrecampo. El pie estrellado, si bien respeta todos los elementos que aparecen en el anterior, es una copia insulsa del mismo. La banda superior de la copa, se reduce vaciando la arcada invertida [1].

La pila de la Villa de Torrefranca, de pequeño tamaño, tiene la singularidad de ser la única de las estudiadas que no está labrada en granito, sino en caliza dura. Tiene un pie bajo, que debió en su día sostenerse sobre otro elemento que le diera altura. La copa la conforma un casquete de esfera sobre el que apoya la banda troncocónica. Su interior es avenerado, tal como el de la pila de Santa Eufemia, con la que compartía señorío. Presenta como decoración exterior gallones y moldura repetitiva. Sobre ésta además, un elemento que circunda la copa a modo de cordón, con nudos en serie de cinco (símbolo de la Orden Franciscana) [2].

Perteneciente a la villa que comparte nombre con su señorío, la de Santa Eufemia es una pila labrada en granito, a pesar de no ser un material muy empleado en la zona, por 


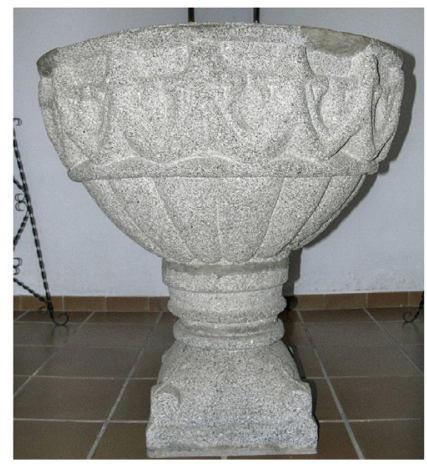

AÑORA

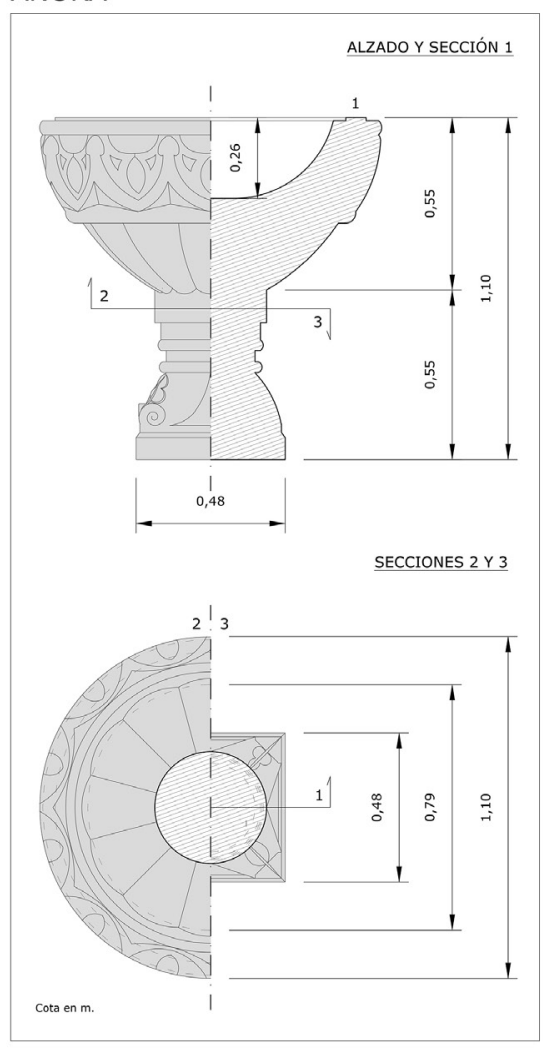

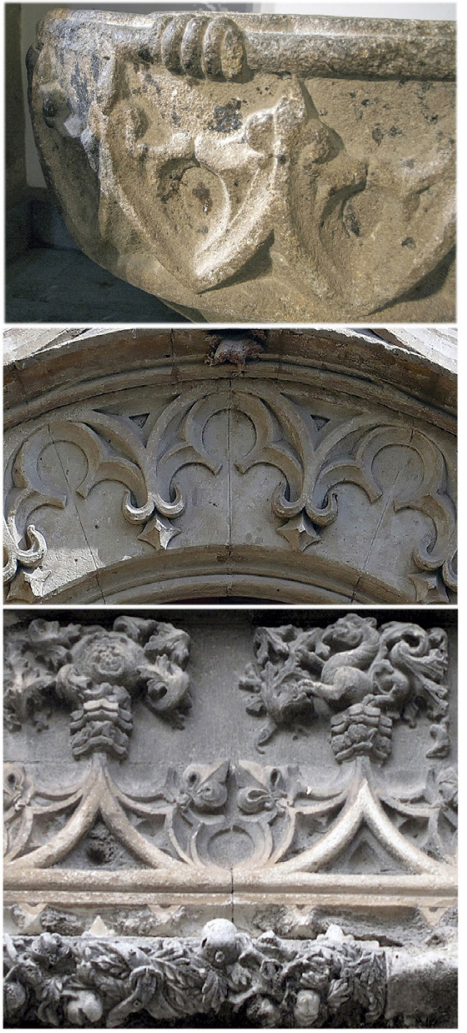

4. A la izquierda, pila bautismal de la parroquia de San Sebastián, Añora (primeras décadas siglo XVI). A la derecha, arriba: detalle de la cenefa ornamental en la copa de la antigua pila bautismal de la parroquia de Santiago de Torrefranca (última década siglo XV). En medio: tracería gótica en las dovelas del arco

del postigo de palacio de la catedral de Córdoba (1464-1476). Abajo: friso gótico flamígero en la fachada este de la catedral de Jaén (1494-1512)

ser el que se encuentra en ella de menor resistencia y no apto para ornamentación. Tiene una amplia copa gallonada en su mitad inferior, y una ancha cenefa en la superior, sobre la que continúan los gallones retranqueados. Su interior está avenerado. El pie es de sección octogonal irregular [2].

La pila de Torremilano es del tipo de inmersión vertical. Tiene una amplia copa de gran profundidad, con gallones cobijados bajo una arcada que los cruza, y una banda decorativa sobre ellos. En este caso, la decoración de la banda se reduce a una cadena de eslabones circulares, con botones concéntricos inscritos. La copa apoya sobre una pequeña basa de sección octogonal con molduras [3].

La pila bautismal de Villanueva del Duque es una pieza de proporciones pequeñas, con ciertas semejanzas a la de Torremilano en su ornamentación. El casquete que compone la zona baja de su copa está adornado con los mismos gallones cobijados bajo arquería. En la banda superior se re- pite la cadena de eslabones circulares, esta vez inscritos con cuadrifolios. Su basa es también similar, aunque de más altura y sección irregular [3].

La de Añora es una pila bautismal esbelta, labrada en granito y compuesta por una copa profunda, fuste y basa. La copa, cónica, presenta gallones bajo arcadas en la mitad inferior, y moldura en la superior. El fuste lo componen varios anillos cilíndricos. La basa, es un capitel de castañuelas o genovés invertido, con volutas simétricas en sus esquinas y hojas de diferentes especies vegetales sobre ellas. Posiblemente sea, junto con la de Santa Eufemia, la más tardía del grupo estudiado [4].

La moldura existente en la banda superior de las copas de las pilas de Torrecampo, Torrefranca, Santa Eufemia y Añora, proviene de un mismo esquema común. Se trata de la modificación de una figura de tracería que viene usándose en el gótico desde el siglo XIII, el arco trilobulado enmarcado al 
intradós de otro mayor, a modo de trifolio abierto. En el caso de dichas pilas, se inscribe en una arquería de medio punto y se voltea el elemento, resultando una singular variación de un motivo ornamental que en origen surgió para solucionar la decoración de vanos, y que aquí se emplea para dar relieve a un bloque macizo. Así los huecos resultantes en forma de triangulaciones y arcos entre las figuras, que en la tracería arquitectónica facilitan la entrada de luz, en este caso quedan cegados, originando meramente hornacinas ornamentales.

A pesar de que los templos a los que pertenecen estas pilas se muestran muy austeros en su decoración (siendo ésta prácticamente inexistente), se dan en la capital cordobesa algunos precedentes arquitectónicos que debieron servir de ejemplo para la labra de estas cenefas.

En el postigo del palacio de la catedral, también llamado de la Paloma, encontramos quizás el mejor ejemplo con que poder establecer la comparación [4]. Fechado en la etapa del episcopado de don Pedro de Córdoba (1464-1476) (Nieto, 2008: 261), se remata con un arco de herradura enmarcado en un alfiz con adornos de estilo gótico flamígero. Las dovelas del arco aparecen decoradas con la dicha arcada de tracería común en la decoración de las pilas. Presenta además otra semejanza con la moldura existente en las pilas bautismales de Torrecampo, Torrefranca y Añora, la coronación con pequeñas flores de lis en la unión de los arcos que componen la seriación.

Las diferencias, además del giro obvio ${ }^{6}$, vienen impuestas tanto por el material de cantería empleado, que imposibilita mejores angulaciones en las piezas de granito, surgiendo un resultado más tosco y menos detallado; como por la deformación del dibujo, que al trasladarse a una matriz lineal se acomoda a la nueva disposición. El arco del trasdós pasa a ser de medio punto, el arco central del intradós aparece prácticamente cerrado sobre sí, y los dos laterales se despliegan y reducen, quedando tan solo en un bosquejo.

Muy similar, y en este caso ya volteada y empleada en una matriz lineal, tal como aparece en las pilas bautismales, es parte de la decoración del friso gótico flamígero de la fachada este de la catedral de Jaén (1494-1512) [4], atribuida a Enrique Egás y al maestro de Cantería Pedro López (Lara, 2009: 23), ambos vinculados con el cabildo de Córdoba en la fecha en que se ejecutó. En esta ocasión, las flores de lis se recolocan en el interior de los arcos, dejando la coronación de las uniones libre para la aparición de otros elementos.

\section{Notas}

1 Archivo General del Obispado de Córdoba (AGOC), Secretaría General, Visitas Generales de Iglesias, 6238/01, 1608.

2 La única referencia encontrada sobre la existencia de canteras de alabastro en la provincia de Córdoba aparece en la información relativa a Cabra del Diccionario Madoz: «También abunda el térm. en canteras de jaspe encarnado de varias clases, de mármoles y aún de alabastro, pero esta última está aún sin beneficiars" (Madoz, 1846: 40).

3 Estaban ejecutadas también en barro las pilas bautismales de las parroquias matrices de Obejo, Santa Cruz, Monturque y posiblemente la de Puente Don Gonzalo. Así como la de San Nicolás de la Axerquía, en Córdoba capital.

4 En bloques de baja calidad se observan grandes manchas oscuras en la superficie, como se muestra en las ilustraciones adjuntas de las pilas de Torremilamo, Villanueva del Duque y Alcaracejos.

5 De otro taller común debieron proceder las pilas de granito de las siete parroquias de los Cortijos de Fuente Obejuna, si bien éstas se ejecutaron en un lapso menor de tiempo, inmediatamente después de mandarse su erección en 1569.

6 Posiblemente el volteo de la figura se deba simplemente a la normal disposición de la copa durante su labrado, bocabajo.

\section{Bibliografía}

LARA LÓPEZ, Emilio Luis (2009), «El friso gótico de la catedral de Jaén: una demonización de los judíos a través de la iconografía», Elucidario. Seminario bio-bibliográfico Manuel Caballero Venzalá, n. 8.

MADOZ, Pascual (1846), Diccionario geográfico-estadístico-histórico de España y sus posesiones de ultramar, tomo 5, Madrid.

NIETO CUMPLIDO, Manuel (2003), Historia de las Diócesis Españolas. Córdoba y Jaén, Biblioteca de Autores Cristianos, Servicio de Publicaciones de Cajasur, Madrid.

- (2008), La Catedral de Córdoba, Servicio de Publicaciones de Cajasur, Córdoba. 